\title{
Trilateral retinoblastoma: neuroimaging characteristics and value of routine brain screening on admission
}

\author{
Firazia Rodjan • Pim de Graaf • Hervé J. Brisse • Sophia Göricke • \\ Philippe Maeder • Paolo Galluzzi · Isabelle Aerts · Claire Alapetite • \\ Laurence Desjardins • Regina Wieland • Maja Beck Popovic • Manuel Diezi • \\ Francis L. Munier - Theodora Hadjistilianou • Dirk L. Knol • Annette C. Moll • \\ Jonas A. Castelijns
}

Received: 1 March 2012 / Accepted: 19 June 2012/Published online: 18 July 2012

(C) The Author(s) 2012. This article is published with open access at Springerlink.com

\begin{abstract}
Trilateral retinoblastoma (TRb) is a rare disease associating intraocular retinoblastoma with intracranial primitive neuroectodermal tumor. Treatment is difficult and prognosis is poor. This multicenter study evaluates clinical findings and MR imaging characteristics of associated intracranial tumors in Rb patients. Clinical data of 17 patients (16 TRb and 1 quadrilateral $\mathrm{Rb}$ patients) included time intervals between $\mathrm{Rb}$ and $\mathrm{TRb}$ diagnosis and presence of baseline brain-imaging (BBI). Two reviewers reviewed all images individually and one reviewer per center evaluated their images. Consensus was reached during a joint scoring session. Studies were reviewed for
\end{abstract}

F. Rodjan $(\bowtie) \cdot$ P. de Graaf · J. A. Castelijns

Department of Radiology, VU University Medical Center,

Postbox 7057, 1007 MB Amsterdam, The Netherlands

e-mail: f.rodjan@vumc.nl

H. J. Brisse

Department of Radiology, Institut Curie, 75248 Paris, France

S. Göricke

Department of Diagnostic and Interventional Radiology and

Neuroradiology, University Hospital, 45122 Essen, Germany

P. Maeder

Department of Radiology, University Hospital, 1011 Lausanne,

Switzerland

P. Galluzzi

Department of Neuroimaging and Neurointerventional (NINT), Azienda Ospedaliera e Universitaria Santa Maria alle Scotte, 53100 Siena, Italy

I. Aerts

Department of Pediatric oncology, Institut Curie, 75248 Paris, France

C. Alapetite

Department of Radiotherapy, Institut Curie, 75248 Paris, France tumor location, size and imaging characteristics (signal intensity (SI) on T1- and T2-weighted images, enhancement pattern and cystic appearance). Of 18 intracranial tumors, $78 \%$ were located in the pineal gland and $22 \%$ suprasellar. All tumors showed well-defined borders with mostly heterogenous enhancement $(72 \%)$ and isointense SI on T1- $(78 \%)$ and T2-weighted images $(72 \%)$ compared to gray matter. The majority of pineal TRbs showed a cystic component $(57 \%)$. TRb detected synchronously with the intraocular tumors on BBI $(n=7)$ were significantly smaller $(P=0.02)$, and mainly asymptomatic than $\mathrm{TRb}$ detected later on $(n=10)$. Overall, 5-year-survival of

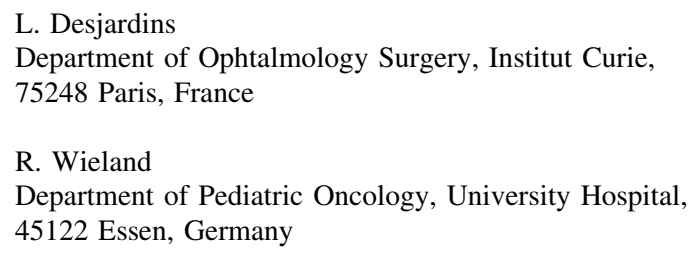

L. Desjardins

Department of Ophtalmology Surgery, Institut Curie,

75248 Paris, France

R. Wieland

Department of Pediatric Oncology, University Hospital,

45122 Essen, Germany

M. B. Popovic · M. Diezi

Department of Pediatric Hematology-Oncology Unit, University

Hospital, 1011 Lausanne, Switzerland

F. L. Munier

Jules Gonin Eye Hospital, University Hospital, 1011 Lausanne,

Switzerland

T. Hadjistilianou

Department of Ophtalmology, Azienda Ospedaliera e

Universitaria Santa Maria alle Scotte, 51300 Siena, Italy

D. L. Knol

Department of Epidemiology and Biostatistics, VU University

Medical Center, 1181 HV Amsterdam, The Netherlands

A. C. Moll

Department of Ophtalmology, VU University Medical Center,

1181 HV Amsterdam, The Netherlands 
TRb patients detected on BBI was $67 \% \quad(95 \%$ CI 29-100\%) compared to $11 \%$ (95\% CI 0-32\%) for the group with delayed diagnosis. TRb mainly develops in the pineal gland and frequently presents with a cystic appearance that could be misinterpreted as benign pineal cysts. Routine BBI in all newly diagnosed $\mathrm{Rb}$ patients can detect $\mathrm{TRb}$ at a subclinical stage.

Keywords Trilateral retinoblastoma - Pineoblastoma · MR imaging · Pediatric oncology $\cdot$ Head and neck

\section{Introduction}

Trilateral retinoblastoma $(\mathrm{TRb})$ is a disease associating unilateral or bilateral retinoblastoma $(\mathrm{Rb})$ with an intracranial midline primitive neuroectodermal tumor (PNET) which usually arises in the pineal gland (PG) (77\%) [1]. In hereditary $\mathrm{Rb}$ patients, the neural ectoderm destined to form both retinal and pineal tissue is prone to develop multifocal neoplasms. This results in histological similar but separate located tumors [2]. The risk of developing $\mathrm{TRb}$ in $\mathrm{Rb}$ patients is less than $0.5 \%$ for sporadic unilateral disease [3], 5-13\% in sporadic bilateral disease, and 5-15\% in familial bilateral $\mathrm{Rb}$ [1]. Patients with $\mathrm{TRb}$ frequently present with signs of intracranial hypertension [3-7]. Few long-term survivors are reported, and, especially in symptomatic patients, prognosis is poor [1, 3, 8-10].

Previous studies on $\mathrm{TRb}$ detection, neuroimaging screening, and prognosis all focused on time intervals between detection of $\mathrm{Rb}$ and $\mathrm{TRb}$ (metachronous tumor development) [1, 10-13]. Reported median time between $\mathrm{Rb}$ and $\mathrm{TRb}$ diagnosis is 21 months $[1,3,9,10]$. However, Kivela et al. [1] reported tha,t with inclusion of brain MR screening during first MRI examination for $\mathrm{Rb}$ (i.e., baseline brain imaging; $\mathrm{BBI}$ ), approximately $50 \%$ of $\mathrm{TRb}$ cases can potentially be found. These are considered synchronous tumors, detected on baseline MRI. Approximately another $25 \%$ of TRbs can be found during the first year after $\mathrm{Rb}$ detection. However, recent literature states that $\mathrm{TRb}$ is rarely present at diagnosis of $\mathrm{Rb}$ [14]. We hypothesize that the exact prevalence of synchronous occurrence of $\mathrm{TRb}$ and $\mathrm{Rb}$ in literature is underestimated. In most studies, it remains unclear whether BBI was performed at $\mathrm{Rb}$ diagnosis, at some time-point during followup or only in a later stage for detection of symptomatic $\mathrm{TRb}$; and if imaging was performed with CT or MR. This complicates the evaluation of "true" synchronous TRb in literature.

Only few radiological articles on $\mathrm{TRb}$ have been reported, and these were mainly individual case reports. To our knowledge, only two studies described radiologic findings on MRI in trilateral retinoblastoma, both within small groups of patients [10, 15]. Because of these modest study populations, it is relevant to identify specific MRI characteristics of TRb in a larger group of patients.

The primary purpose of this multicenter study was to evaluate clinical findings and MRI characteristics of associated intracranial tumors in $\mathrm{Rb}$ patients. The secondary purpose was to assess clinical, radiological and prognostic differences between $\mathrm{TRb}$ depicted on $\mathrm{BBI}$ and those depicted later on.

\section{Materials and methods}

\section{Patient population}

This retrospective study was performed in agreement with the recommendations of the local ethics committees within a European Retinoblastoma Imaging Center (ERIC) with five participating $\mathrm{Rb}$ centers. Review of clinical records between 1991 and 2010, revealed $17 \mathrm{Rb}$ patients with MRI and intracranial tumors. TRb was diagnosed on the basis of histopathological confirmation [surgery or presence of tumor cells in cerebrospinal fluid (CSF)] or clinical disease progression during follow-up MRI. TRb was defined as a mass lesion in the PG or suprasellar region in $\mathrm{Rb}$ patients. Tumor in both $\mathrm{PG}$ and suprasellar regions in combination with bilateral $\mathrm{Rb}$ was classified as a quadrilateral $\mathrm{Rb}(\mathrm{QRb})$.

\section{Record review}

Clinical records were reviewed for tumor laterality, family history for $\mathrm{Rb}$, age of $\mathrm{Rb}$ diagnosis, time interval from $\mathrm{Rb}$ to $\mathrm{TRb}$ diagnosis and $\mathrm{TRb}$ diagnosis to death or last followup date. Symptoms at first presentation of $\mathrm{TRb}$ and treatment received for $\mathrm{Rb}$ and $\mathrm{TRb}$ were recorded. Laboratory records were analyzed for tumor cells in CSF acquired by lumbar puncture (LP) performed either at diagnosis or during follow-up. Particular attention was paid to the presence of $\mathrm{BBI}$, which is necessary to evaluate the simultaneous occurrence of $\mathrm{TRb}$ at $\mathrm{Rb}$ diagnosis. $\mathrm{TRb}$ were categorized in synchronous or metachronous tumors to the intraocular tumor. Patients with bilateral retinoblastoma, a positive family history of retinoblastoma or mutations in the RB1 gene found in chromosomal/DNA analysis were classified as hereditary. Disease progression was defined as either tumor recurrence, intracranial or intraspinal leptomeningeal spread or distant metastases.

Image review

Patients underwent various imaging protocols for the assessment of TRb. MRI sequences varied in different 
Table 1 Clinical patient characteristics

\begin{tabular}{|c|c|c|c|c|c|c|c|c|c|c|c|}
\hline $\begin{array}{l}\text { Patient } \\
\text { (Rb lat) }\end{array}$ & $\begin{array}{l}\text { Confirmation } \\
\text { TRb }\end{array}$ & $\begin{array}{l}\text { Age } \\
\mathrm{Rb}\end{array}$ & $\begin{array}{l}\text { Age } \\
\text { TRb }\end{array}$ & $\begin{array}{l}\text { Int. Rb- } \\
\mathrm{TRb}\end{array}$ & $\begin{array}{l}\text { Year Rb } \\
\text { date }\end{array}$ & $\mathrm{BBI}$ & Death & $\begin{array}{l}\text { Int TRb } \\
\text { death }\end{array}$ & $\begin{array}{l}\text { Int TRb } \\
\text { FU }\end{array}$ & $\begin{array}{l}\text { Treatment RB } \\
\text { (OD; OS) }\end{array}$ & $\begin{array}{l}\text { Treatment } \\
\mathrm{TRb}\end{array}$ \\
\hline 1 (B) & Histopathology & 3 & 52 & 49 & 1986 & No & Yes & 57 & 57 & PT & ChT, EBRT \\
\hline $2(\mathrm{~B})$ & CSF & 2 & 39 & 37 & 1990 & No & Yes & 21 & 21 & EBRT & ChT, EBRT \\
\hline $3(\mathrm{~B})$ & Histopathology & 5 & 10 & 5 & 1991 & No & Yes & 7 & 7 & En; EBRT & Palliation \\
\hline 4 (B) & DP on MR & 23 & 38 & 15 & 1992 & No & Yes & 0 & 0 & EBRT & Palliation \\
\hline $5(\mathrm{~B})$ & CSF & 2 & 26 & 24 & 1992 & No & Yes & 13 & 13 & CrT; En. & ChT \\
\hline $6(\mathrm{~B})$ & DP on MR & 12 & 12 & 0 & 1997 & Yes & Yes & 14 & 14 & CrT, En. & No \\
\hline $7(\mathrm{U})$ & CSF & 3 & 57 & 54 & 1997 & No & No & & 93 & No; En. & ChT \\
\hline $8(\mathrm{~B})$ & Histopathology & 2 & 42 & 40 & 1998 & No & $\mathrm{Yes}^{\mathrm{a}}$ & 11 & 11 & ChT & $\begin{array}{c}\text { ChT, EBRT, } \\
\text { surgery }\end{array}$ \\
\hline 9 (B) & $\mathrm{DP}$ on $\mathrm{MR}$ & 3 & 3 & 0 & 2000 & Yes & No & & 74 & ChT/CrT; En. & ChT \\
\hline $10(\mathrm{~B})$ & CSF & 17 & 17 & 0 & 2001 & Yes & Yes & 7 & 7 & ChT & ChT \\
\hline $11(\mathrm{~B})$ & $\mathrm{CSF}$ & 3 & 15 & 12 & 2001 & No & $\mathrm{NA}^{\mathrm{b}}$ & & 3 & CrT; En. & ChT \\
\hline 12 (B) & $\mathrm{CSF}$ & 7 & 23 & 16 & 2002 & No & Yes & 16 & 16 & En; En & ChT \\
\hline $13(\mathrm{~B})$ & $\mathrm{CSF}$ & 1 & 31 & 30 & 2002 & No & Yes & 15 & 15 & ChT; CrT & ChT, surgery \\
\hline $14(\mathrm{~B})$ & CSF & 10 & 10 & 0 & 2003 & Yes & No & & 50 & ChT & ChT \\
\hline $15(\mathrm{~B})$ & CSF & 12 & 12 & 0 & 2005 & Yes & No & & 63 & ChT, CrT; & ChT \\
\hline $16(\mathrm{U})$ & Histopathology & 10 & 10 & 0 & 2006 & Yes & No & & 56 & ChT & ChT, surgery \\
\hline $17(\mathrm{U})$ & No & 38 & 38 & 0 & 2008 & Yes & NA & NA & NA & No; En. & NA \\
\hline
\end{tabular}

$R b$ lat laterality $\mathrm{Rb}, B$ bilateral $\mathrm{Rb}, U$ unilateral $\mathrm{Rb}$, Int. $R b-T R b$ interval between $\mathrm{Rb}$ and $\mathrm{TRb}$ in months, Int TRb death interval $\mathrm{TRb}$ and death in months, Int TRb FU interval of follow-up in months, $C S F$ cerebrospinal fluid, $D P$ disease progression, $B B I$ baseline brain imaging, $P T$ plaque therapy, $C h T$ chemotherapy, EBRT external beam radiation therapy, $C r T$ cryotherapy, $N A$ not available

${ }^{a}$ Due to intoxicity after chemotherapy

b Lost to follow-up after 3 months with progressive disease

institutions. Brain MRI protocols at least included either sagittal or transverse unenhanced T1-weighted images or T2-weighted images in 14 patients. Post-contrast T1weighted images of $\mathrm{TRb}$ were available in 16 patients.

Two observers (JC and PdG) with, respectively, 22 years and 10 years experience individually reviewed all MRI examinations and one radiologist from each participating center (HJB, PG, PM and SG) evaluated their images. Agreement was reached during a joint scoring session. MR images were evaluated for mass lesions in the PG and suprasellar regions and for leptomeningeal tumor dissemination. Regarding the $\mathrm{TRb}$, maximal axial diameter (MAD) at diagnosis, tumor border, presence of tumor necrosis, tumor aspect (solid, solid with cystic component,; or complete cystic), SI on T1- and T2-weighted images compared to gray matter, aspect of contrast enhancement, presence of vessel encasement, and hydrocephalus and leptomeningeal metastases were scored.

\section{Statistics}

Statistical calculations were performed using SPSS v.15.0 (SPSS, Chicago, IL, USA). BBI and MAD were analyzed by using the Mann-Whitney test. Difference in mean MAD between pineoblastomas and suprasellar tumors was analyzed using an independent $t$ test. Associations between other clinical dichotomous parameters and BBI were assessed using Fisher exact tests. A $95 \%$ CI for 5-year survival was calculated based upon the Kaplan-Meier survival function. A $P$ value of less than 0.05 was considered statistically significant.

\section{Results}

Clinical findings

Clinical data of part of this study have been previously reported (Table 1) [1]. Ten patients had familial $\mathrm{Rb}(59 \%)$ and 11 patients also a positive RB1-gene mutation (65\%). Sixteen patients (94\%) were classified as hereditary $\mathrm{Rb}$. Mean age of $\mathrm{Rb}$ diagnosis was 9 months (median age 5 months) and of TRb 26 months (median age, 23 months). Mean time-interval between detection of $\mathrm{Rb}$ and $\mathrm{TRb}$ was 18 months (median, 14 months). In none of the patients, $\mathrm{TRb}$ was found before $\mathrm{Rb}$.

Nine patients had signs of intracranial hypertension, whereas the other 8 patients were asymptomatic at 
Table 2 Imaging characteristics

\begin{tabular}{|c|c|c|c|c|c|c|c|c|c|c|c|}
\hline Patient & $\begin{array}{l}\text { Intracranial } \\
\text { tumor } \\
\text { location }\end{array}$ & MAD & $\begin{array}{l}\text { Tumor } \\
\text { border }\end{array}$ & $\mathrm{AL}$ & Necrosis & SIT1 & SIT2 & Enhancement & LM & Hydrocephalus & VE \\
\hline 1 & PG & 25 & Well defined & Solid & No & NA & NA & Homogeneous & No & Yes & Yes \\
\hline 2 & PG & 55 & Well defined & $\mathrm{PC}$ & Yes & Isointense & Hypointense & Heterogeneous & No & Yes & Ye \\
\hline 3 & PG & 59 & Well defined & $\mathrm{PC}$ & Yes & Isointense & Isointense & Heterogeneous & No & Yes & Ye: \\
\hline 4 & PG & 49 & Well defined & $\mathrm{PC}$ & Yes & Hypointense & Isointense & Heterogeneous & Yes & Yes & $\mathrm{Ye}$ \\
\hline 5 & PG & 18 & Well defined & Solid & No & Isointense & Hypointense & Heterogeneous & Yes & Yes & No \\
\hline 6 & PG & 9 & Well defined & Cystic & Yes & Isointense & Isointense & Heterogeneous & No & No & No \\
\hline 7 & PG & 51 & Well defined & $\mathrm{PC}$ & Yes & Isointense & Isointense & Heterogeneous & $\mathrm{Ntb}$ & Yes & No \\
\hline 8 & PG & 22 & Well defined & Solid & Yes & Isointense & Isointense & Heterogeneous & No & Yes & No \\
\hline 9 & PG & 13 & Well defined & Cystic & No & NA & NA & Heterogeneous & No & No & No \\
\hline 10 & SS & 15 & Well defined & Solid & No & Isointense & Isointense & Homogeneous & No & No & No \\
\hline 11 & PG & 13 & Well defined & Solid & Yes & Isointense & Isointense & NA & $\mathrm{Ntb}$ & No & No \\
\hline 12 & PG & 11 & Well defined & Solid & Yes & NA & Isointense & Heterogeneous & No & No & Yes \\
\hline 12 & SS & 44 & Well defined & Solid & No & NA & Isointense & Homogeneous & No & No & Yes \\
\hline 13 & PG & 33 & Well defined & Solid & Yes & Isointense & Isointense & Heterogeneous & Yes & Yes & No \\
\hline 14 & SS & 23 & Well defined & Solid & No & Isointense & Isointense & Homogeneous & No & No & No \\
\hline 15 & SS & 34 & Well defined & $\mathrm{PC}$ & Yes & Isointense & Isointense & Heterogeneous & Yes & No & No \\
\hline 16 & PG & 21 & Well defined & Cystic & Yes & Isointense & Isointense & Heterogeneous & No & No & No \\
\hline 17 & PG & 11 & Well defined & Cystic & Yes & Isointense & NA & Heterogeneous & No & No & No \\
\hline
\end{tabular}

$P G$ pineal gland, $S S$ supra sellar, $M A D$ maximal axial diameter, $A L$ aspect lesion, $P C$ partly cystic, $N A$ not available, $S I T 1$ signal intensity on T1weighted images compared to gray matter, SI T2 signal intensity on T2-weighted images compared to gray matter, $L M$ leptomeningeal metasteses, $V E$ vessel encasement

detection. LP at baseline were performed in 7 patients (positive for tumor cells in 5 patients) and during follow-up in 11 patients (positive in 5 additional patients). Histopathologic specimens were available in $4 \mathrm{TRbs}$ and were classified as PNETs. Rb was treated with external beam radiotherapy (EBRT) (mean age 10 months, median 5 months) in 3 out of 10 metachronous patients. These patients developed $\mathrm{TRb}$ after a mean interval of 19 months (range 5-37 months). $\mathrm{Rb}$ was treated with chemotherapy in 2 out of 10 metachronous $\mathrm{TRb}$ patients (mean interval 35 months; range 30-40 months). Treatment for TRb was initiated in 13 patients. Two patients received palliative treatment because of tumor spread, one patient was not treated because of parental refusal, and one patient was lost of follow-up.

\section{MRI characteristics of $\mathrm{TRb}$}

MRI characteristics are summarized in Table 2. In our group of 17 patients, 18 intracranial tumors were detected.

Of the 14 pineoblastomas, $6(42 \%)$ showed a completely solid aspect (Fig. 1a), 4 (29\%) solid with cystic component (Fig. 2), and 4 (29\%) were completely cystic with an irregularly thickened rim (Fig. 3). Pineoblastomas mimicking pineal cysts showed an irregular (patient 6; Fig. 3a) or thickened (patient 16; Fig. 3c) cyst wall, sometimes with tiny nodules. Follow-up imaging in patient 6 showed progression of the pineal lesion into a solid tumor with diffuse leptomeningeal metastases 14 months after refusal of treatment (Fig. 3b). Patient 16 showed an obvious solid tumor part on the axial MR images (Fig. 3d). Secondary hydrocephalus occurred in 8 patients $(57 \%)$ with pineoblastoma (Figs. 1b, 2b) and leptomeningeal metastases in 3 patients ( $21 \%$ ) (Figs. 1d, 2b). One suprasellar tumor showed a homogenous solid aspect with a cystic component (Fig. 2a).

Overall, the mean MAD was $30 \mathrm{~mm}$ (range 9-59 mm).

Clinical and radiological patterns according to time of diagnosis

BBI was available in 7 cases and in all $\mathrm{Rb}$ and $\mathrm{TRb}$ were diagnosed simultaneously (mean age 15 months, median 12 months; range 3-38 months). These 7 patients did not have any signs of intracranial hypertension at first presentation.

In the remaining 10 patients without $\mathrm{BBI}$, mean interval between $\mathrm{Rb}$ and $\mathrm{TRb}$ diagnosis was 27 months (median 24 months; range 5-54 months). Symptoms of intracranial hypertension occurred in 8 patients. A significant difference was observed in tumorsize $(P=0.02)$ and hydrocephalus $(P=0.002)$ in favour of patients with BBI. In 1 patient with $\mathrm{TRb}$, no symptoms occurred, and in $1 \mathrm{QRb}$ patient, 

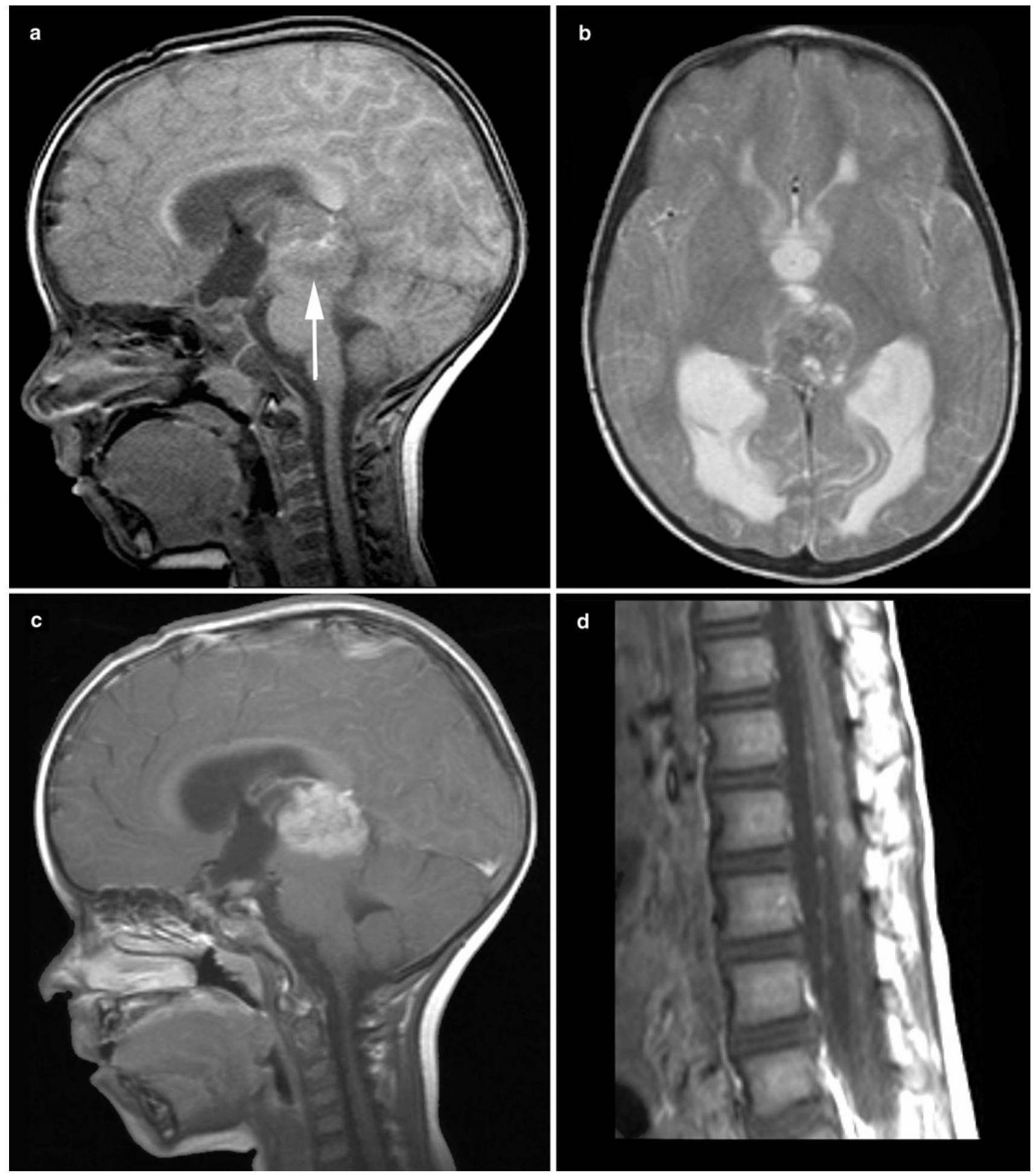

Fig. 1 Solid pineoblastoma with hydrocephalus and extensive leptomeningeal metastases. Sagittal T1-weighted (a), axial T2-weighted (b), contrast-enhanced sagittal T1-weighted images of the brain (c) and spine (d) of patient 13. Pineoblastoma showed mostly isointense SI on both T1-weighted (a) and T2-weighted (b) MR images with respect to gray matter and homogenous contrastenhancement (c). The large tumor mass $(33 \mathrm{~mm})$ showed compression on the brainstem (mesencephalon) and cerebral aquaduct $(\mathbf{a}, \mathbf{c})$ with secondary hydrocephalus (b). Multiple nodular leptomeningeal tumor seedings are present in the spinal canal (d) 


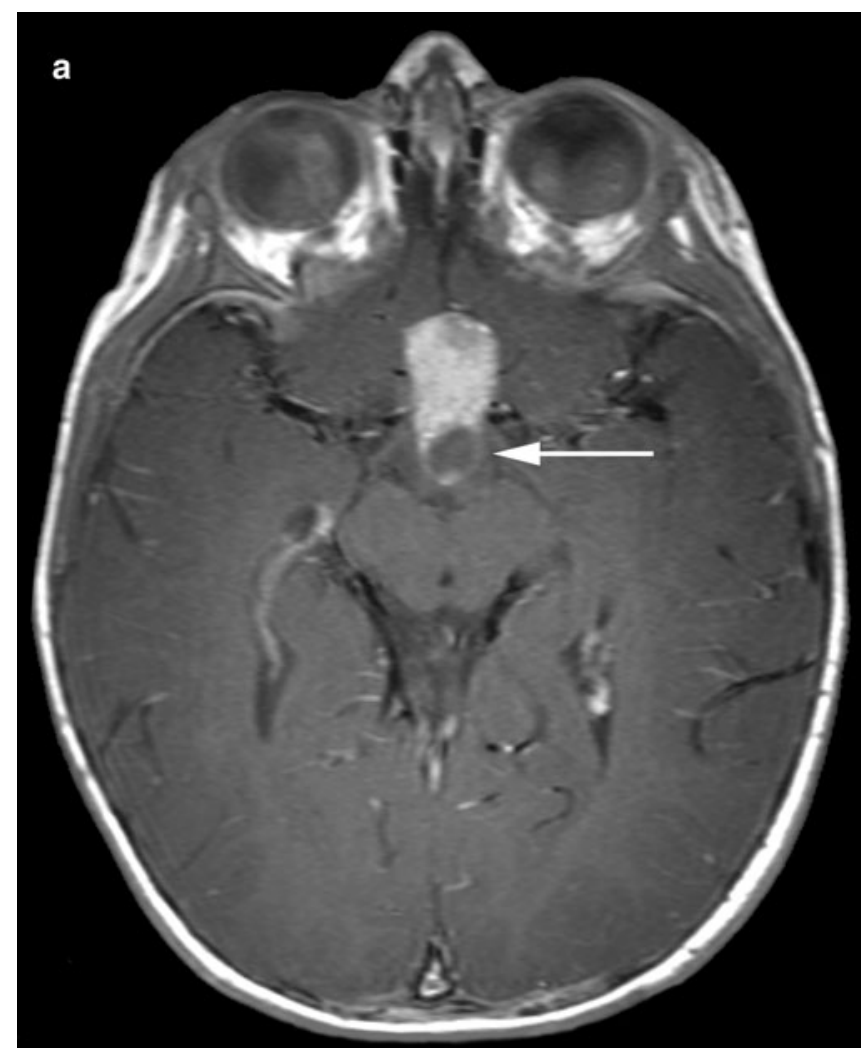

Fig. 2 Suprasellar and pineal gland trilateral retinoblastoma. Contrast-enhanced axial T1-weighted images showing solid tumor masses with cystic components in both the suprasellar region (patient 15)

symptoms could not be retrieved from the clinical records. Furthermore, other differences were observed in the patients with BBI compared to patients without BBI. Tumor size was significantly smaller in patients with BBI [mean MAD $18 \mathrm{~mm}$ (range 9-34 mm)] compared to patients without BBI [mean MAD $35 \mathrm{~mm}$ (range 11-59 mm)] $(P=0.02)$. Hydrocephalus $(P=0.002)$ occurred more often in patients without BBI and thus in larger tumors. Lumbar puncture in patients with BBI was positive in $29 \%$ of the cases and $70 \%$ in patients without BBI $(P=0.15)$.

In addition, more synchronous tumors were detected after the year 2000 as illustrated in Table 1, because BBI was more routinely included in current imaging protocols.

\section{Survival}

One out of 17 patients was lost to follow-up and excluded from survival analysis. One out of the remaining 16 patients was treated with chemotherapy and lost to followup after 3 months with progressive disease, and one died from intoxicity after intensive chemotherapy.

Five out of 16 patients $(33 \%)$ are still alive (mean survival, 67 months; median 63 months, range, 50-93 months). Four of these 5 patients $(80 \%)$ presented with synchronous TRb detected on BBI and were free of disease

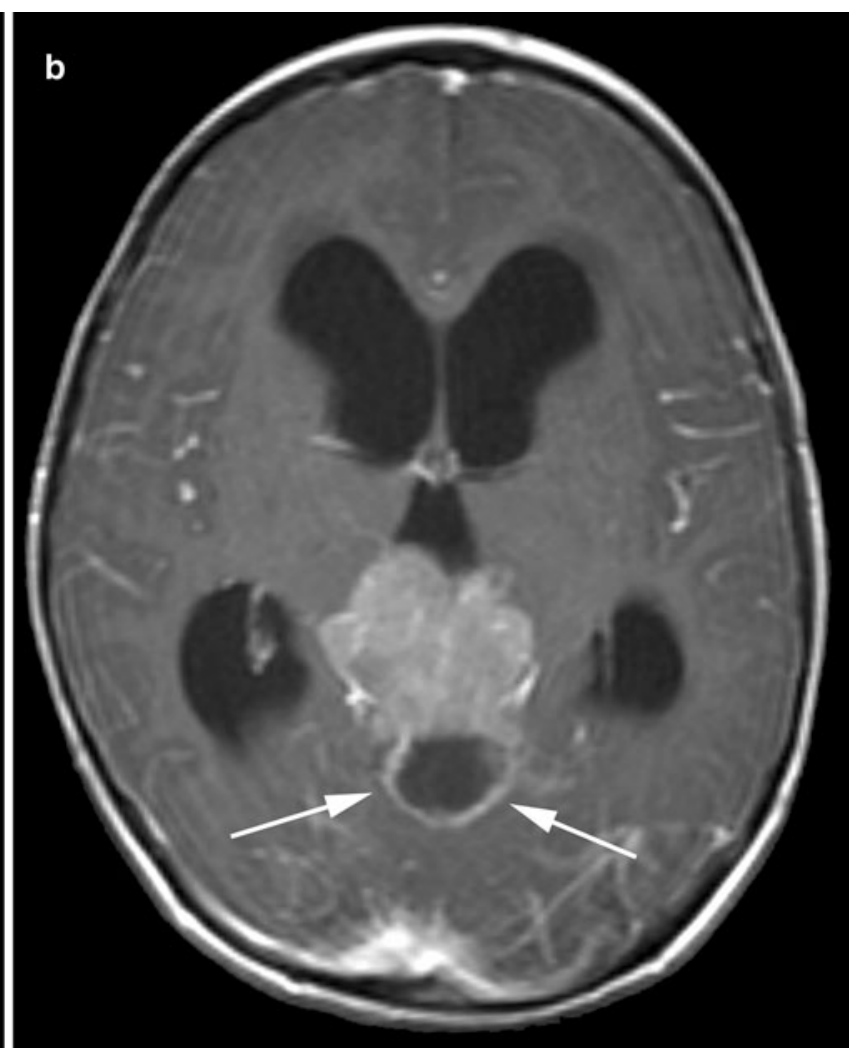

(a) and pineal gland (patient 7) (b). The pineal gland mass causes a secondary hydrocephalus because of brainstem compression (b)

(mean survival, 61 months; range 50-74 months). The other survivor was diagnosed with a pineoblastoma of $51 \mathrm{~mm}$ (54 months after $\mathrm{Rb}$ diagnosis without $\mathrm{BBI}$ ). This patient had local tumor recurrences but is still in second complete remission, 93 months after complete resection of the pineoblastoma and intensive chemotherapy.

The remaining 10 patients died after a mean interval of 24 months. Eight presented with metachronous TRb and without BBI. Cause of death in these 10 patients included local spread of the initial TRb (3 patients), leptomeningeal metastases (4 patients), tumor recurrence (2 patients), and side effects of intensive chemotherapy (1 patient).

Difference in survival of PNET early detected with BBI compared to those with delayed diagnosis was not significant $(P=0.064)$. The overall 5-year survival of PNET detected on BBI was $67 \%$ (95 \% CI 29-100 \%) compared to $11 \%$ (95\% CI 0-32\%) for the group without BBI.

\section{Discussion}

The most important imaging finding of this retrospective analysis is that the majority of the pineoblastomas in our study were partially or totally cystic. Other main findings are that TRbs detected synchronously with the Rb on BBI 

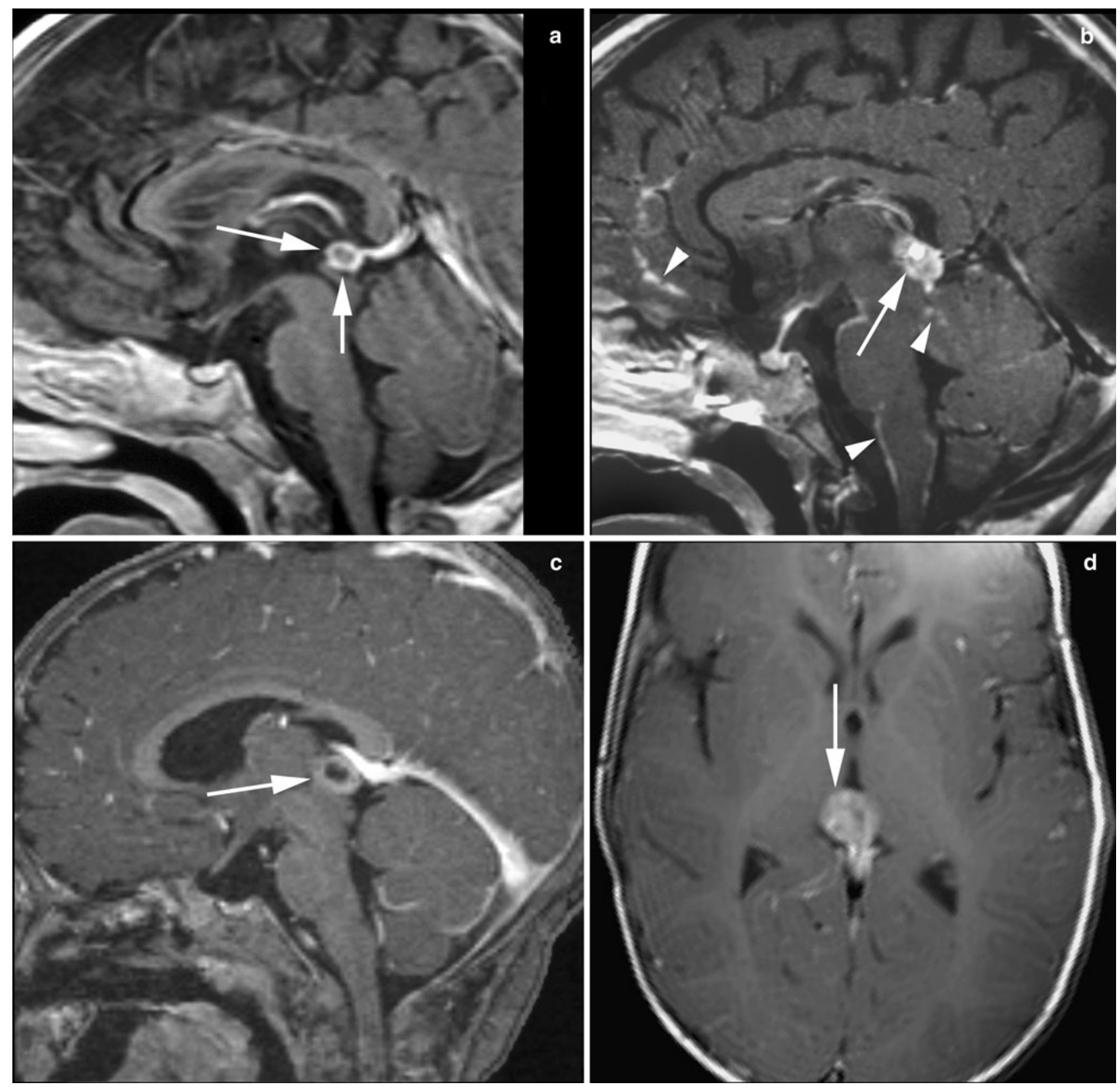

Fig. 3 Pineoblastoma presenting as suspicious cyst. Contrastenhanced sagittal $(\mathbf{a}-\mathbf{c})$ and axial (d) T1-weighted images of the brain in patient $6(\mathbf{a}, \mathbf{b})$ and patient $16(\mathbf{c}, \mathbf{d})$. The pineal gland in a shows an irregular cyst wall with tiny nodules, which progressed

were significantly smaller, more frequently asymptomatic, and could have a better prognosis compared to TRbs found after diagnosis of $\mathrm{Rb}$ (metachronous TRBs).

In the literature, the simultaneous occurrence of $\mathrm{Rb}$ and intracranial tumor is rare $[14,16]$. Kivela et al. [1] reported that intracranial tumors were detected before $\mathrm{Rb}$ diagnosis in $3 \%$ of the cases, $14 \%$ simultaneously with $\mathrm{Rb}$, and $83 \%$ after Rb diagnosis. However, the incidence of synchronous $\mathrm{TRb}$ is probably underestimated, as historically into a solid tumor with diffuse (nodular) leptomeningeal metastases 14 months later after treatment refusal (b). The pineal gland in patient 16 mimics a pineal cyst on the sagittal image (c), but shows a solid part of the lesion on the axial image (d), suspicious for pineoblastoma

little documentation about the presence of $\mathrm{BBI}$ at $\mathrm{Rb}$ diagnosis is available. Most TRbs described are diagnosed after first presentation with symptoms and signs of intracranial hypertension. Diagnosis and treatment for retinoblastoma is usually completed by then [3-7]. In our study, in all patients with synchronous tumors detected on BBI, significantly smaller TRbs were detected compared to metachronous TRb. Furthermore, $70 \%$ of patients with metachronous tumors presented with symptoms due to 
intracranial hypertension and $80 \%$ died due to their intracranial tumor. This indicates that the majority of metachronous tumors could have been detected in an earlier stage if BBI would have been performed. Remarkably, the majority of synchronous tumors were detected in TRb patients after the year 2000, as cerebral imaging was performed more frequently in our centers. We found a lower median time-interval of 14 months in our group compared to a median time interval of 21 months mentioned in literature $[1,13]$. In these studies, however, the majority of the TRbs ( 83 and $62 \%$, respectively) were detected after diagnosis and treatment for $\mathrm{Rb}$, while in our study a higher rate of synchronous tumors ( $41 \%$ ) were present.

Pineoblastomas and suprasellar tumors presented as typically well-defined lesions with relatively isointense SI on T1-weighted and T2-weighted images compared to gray matter. Contrast enhancement in these tumors was mostly heterogenous due to cystic components or tumor necrosis. Similar SIs on T1-weighted images were reported in 4 and 8 patients, respectively, on MRI [10, 15], but diverse enhancement patterns and SIs on T2-weighted images have been described [13, 15, 17, 18]. Hydrocephalus was a typical complication of large pineoblastomas. Therefore, we stress the need for BBI to detect smaller TRbs.

The majority of the pineoblastomas in our study were partially or totally cystic. Pineal cysts have been reported in $\mathrm{Rb}$ patients but not associated with hereditary $\mathrm{Rb}$ [19]. The presence of suspicious pineal cystic tumors, however, are a point of discussion [19-24]. Because of life-threatening side effects that may be related with curative aggressive treatment in TRb patients [25], it is important that cysts are not misinterpreted as tumor. Pineal cysts are diagnosed if (1) an enlarged PG is present, (2) with a hypointense central region with respect to white matter on T1-weighted-images and isointense with respect to CSF on T2-weighted images, and (3) a thin wall of $2 \mathrm{~mm}$ or less with discrete rim enhancement after gadolinium injection [20]. Although these criteria are formulated, pineal lesions in retinoblastoma are causing radiological dilemmas, especially if the cyst wall is irregularly thickened $(>2 \mathrm{~mm}$ ) or shows a fine nodular aspect of the wall $[19,20]$. In our study, only 6 out of 14 pineoblastomas were completely solid, whereas $29 \%$ (4 tumors) had both a cystic and solid component, and 4 tumors mimicked a pineal cyst. Hence, the need for imaging characteristics of early stage (cystic) pineoblastoma and follow-up scheme in suspicious cystic lesions of the PG is necessary to separate these from benign pineal cysts. Identification of such criteria is only possible in a large group of suspicious cystic PGs in Rb patients. Because these tumors are rare, a multicentric prospective study is necessary to define evident criteria for detection of early stage (cystic) pineoblastoma. Meanwhile, we recommend that pineal cystic lesions depicted on BBI should be classified into three groups: (1) "probably benign pineal cyst", (2) "obvious cystic pineoblastoma", or (3) "suspicious pineal cyst". The first group contains patients with a cystic PG with discrete rim enhancement and a thin smooth wall; we recommend repeating MRI once after 6 months and, if stable, no further follow-up. The third group requires close MR follow-up after 3 months. As, currently, MRI of every new $\mathrm{Rb}$ patient is performed routinely in most centers, screening could easily be obtained by performing at least one brain MR sequence [26]. This screening could be achieved by a post-contrast 3D T1-weighted sequence with $1 \mathrm{~mm}$ slice thickness, and if a cystic portion is detected in the PG, an additional $2 \mathrm{~mm}$ T2-weighted sequence or thin slice 3D T2/CISS can further characterize the lesion.

In our series, a trend was observed for a better survival of patients who had PNET detected early with BBI. However, due to the small sample size, this difference did not reach significance. Several studies advise brain imaging screening in $\mathrm{Rb}$ patients in order to detect $\mathrm{TRb}$ in an early stage $[1,9,27]$. Although improvement of prognosis in $\mathrm{TRb}$ patients is important, caution with screening programs should be considered. First, prognosis of TRb patients detected by screening compared to patients with symptomatic disease should be evaluated. Duncan et al. [12] were the first to evaluate screening for $\mathrm{TRb}$ with $\mathrm{CT}$ at baseline and additional brain MRI every 6 months in 83 hereditary $\mathrm{Rb}$ patients. No improved outcome was observed despite early diagnosis. Kivela et al. [1], discovered that screening identified TRb in an earlier stage, but without better survival. This indicates that longer survival was due to lead-time bias. A disadvantage of early detection without better outcome is severe treatment-related morbidity and distress in these children leading to lower quality of life. In recent literature, however, highdose chemotherapy has successfully been introduced for $\mathrm{TRb}$, gradually leading to an increase in survival time [14, 28]. Especially, TRb detected in an early stage could benefit from these new treatment strategies, since reported survivors are almost inevitably the synchronous or early metachronous patients. These early metachronous patients ( $\mathrm{TRb}$ diagnosed a few months after $\mathrm{Rb}$ diagnosis) should be classified as "missed synchronous" rather than "early metachronous". Therefore, we stress the need for routine brain MRI in every single newly diagnosed retinoblastoma patient on admission, which is a potentially simple and (cost-)effective screening method for early TRb detection. The value of extending brain MRI screening after BBI is under discussion and therefore sporadically applied in European retinoblastoma referral centers.

The rare incidence of $\mathrm{TRb}$ in all participating $\mathrm{Rb}$ centers in Europe is in agreement with the observed declining incidence of TRb over the last decades [29-31] and is still a 
matter of debate. An increasing use of neoadjuvant chemotherapy for intraocular retinoblastoma (chemoreduction) preventing development of $\mathrm{TRb}$ has been suggested by Shields et al. [31], who registered fewer TRb since the introduction of chemoreduction as primary treatment for $\mathrm{Rb}$. However, cases of $\mathrm{TRb}$ are reported even after an intensive scheme of chemoreduction therapy in advance [32]. In our study, 2 out of 10 metachronous TRb patients received chemotherapy and still developed TRb. The decreasing incidence of TRb could be due to the declining use of EBRT in patients with hereditary retinoblastoma [33]. In 3 patients, intraocular $\mathrm{Rb}$ was treated with EBRT, and these patients developed metachronous pineoblastomas.

A limitation of this study is the absence of BBI in all included metachronous TRbs. Therefore, the true incidence of metachronous $\mathrm{TRb}$ is still likely to be overestimated. Also, the small size of our patient cohort was a study limitation for statistical analysis.

In conclusion, TRb mainly develops in the PG and frequently presents with a cystic appearance that may be misleading. We recommend a three-group classification of pineal cystic lesions depicted in $\mathrm{Rb}$ patients. Routine $\mathrm{BBI}$ in all newly diagnosed $\mathrm{Rb}$ is strongly recommended as it may detect $\mathrm{TRb}$ in a subclinical and potentially curable stage.

Acknowledgements This study was financially supported by grants from the ODAS Foundation, Delft, The Netherlands, the National Foundation for the Blind and Visually Impaired, Utrecht, The Netherlands, and the Blindenhulp Foundation, 's Gravenhage, The Netherlands.

Conflicts of interest We confirm that the authors do not have any conflicts of interest, financial disclosures and acknowledgements.

Open Access This article is distributed under the terms of the Creative Commons Attribution License which permits any use, distribution, and reproduction in any medium, provided the original author(s) and the source are credited.

\section{References}

1. Kivela T (1999) Trilateral retinoblastoma: a meta-analysis of hereditary retinoblastoma associated with primary ectopic intracranial retinoblastoma. J Clin Oncol 17:1829-1837

2. Bader JL, Miller RW, Meadows AT, Zimmerman LE, Champion LA, Voute PA (1980) Trilateral retinoblastoma. Lancet 2: 582-583

3. De Potter P, Shields CL, Shields JA (1994) Clinical variations of trilateral retinoblastoma: a report of 13 cases. J Pediatr Ophthalmol Strabismus 31:26-31

4. Michaud J, Jacob JL, Demers J, Dumas J (1984) Trilateral retinoblastoma: bilateral retinoblastoma with pinealoblastoma. Can $\mathbf{J}$ Ophthalmol 19:36-39

5. Whittle IR, McClellan K, Martin FJ, Johnston IH (1985) Concurrent pineoblastoma and unilateral retinoblastoma: a forme fruste of trilateral retinoblastoma? Neurosurgery 17:500-505

6. Bejjani GK, Donahue DJ, Selby D, Cogen PH, Packer R (1996) Association of a suprasellar mass and intraocular retinoblastoma: a variant of pineal trilateral retinoblastoma? Pediatr Neurosurg 25:269-275

7. Holladay DA, Holladay A, Montebello JF, Redmond KP (1991) Clinical presentation, treatment, and outcome of trilateral retinoblastoma. Cancer 67:710-715

8. Jubran RF, Erdreich-Epstein A, Butturini A, Murphree AL, Villablanca JG (2004) Approaches to treatment for extraocular retinoblastoma: children's Hospital Los Angeles experience. J Pediatr Hematol Oncol 26:31-34

9. Paulino AC (1999) Trilateral retinoblastoma: is the location of the intracranial tumor important? Cancer 86:135-141

10. Provenzale JM, Gururangan S, Klintworth G (2004) Trilateral retinoblastoma: clinical and radiologic progression. Am J Roentgenol 183:505-511

11. Blach LE, McCormick B, Abramson DH, Ellsworth RM (1994) Trilateral retinoblastoma-incidence and outcome: a decade of experience. Int J Radiat Oncol Biol Phys 29:729-733

12. Duncan JL, Scott IU, Murray TG, Gombos DS, van Quill K, O'Brien JM (2001) Routine neuroimaging in retinoblastoma for the detection of intracranial tumors. Arch Ophthalmol 119:450 452

13. Provenzale JM, Weber AL, Klintworth GK, McLendon RE (1995) Radiologic-pathologic correlation. Bilateral retinoblastoma with coexistent pinealoblastoma (trilateral retinoblastoma). Am J Neuroradiol 16:157-165

14. Wright KD, Qaddoumi I, Patay Z, Gajjar A, Wilson MW, Rodriguez-Galindo C (2010) Successful treatment of early detected trilateral retinoblastoma using standard infant brain tumor therapy. Pediatr Blood Cancer 55:570-572

15. Bagley LJ, Hurst RW, Zimmerman RA, Shields JA, Shields CL, De PP (1996) Imaging in the trilateral retinoblastoma syndrome. Neuroradiology 38:166-170

16. Antoneli CB, Ribeiro KC, Sakamoto LH, Chojniak MM, Novaes PE, Arias VE (2007) Trilateral retinoblastoma. Pediatr Blood Cancer 48:306-310

17. Cho EY, Suh YL, Shin HJ (2002) Trilateral retinoblastoma: a case report. J Korean Med Sci 17:137-140

18. Jurkiewicz E, Pakula-Kosciesza I, Rutynowska O, Nowak K (2010) Trilateral retinoblastoma: an institutional experience and review of the literature. Childs Nerv Syst 26:129-132

19. Rodjan F, de Graaf P, Moll AC et al (2010) Brain abnormalities on MR imaging in patients with retinoblastoma. Am J Neuroradiol 31:1385-1389

20. Beck PM, Balmer A, Maeder P, Braganca T, Munier FL (2006) Benign pineal cysts in children with bilateral retinoblastoma: a new variant of trilateral retinoblastoma? Pediatr Blood Cancer 46:755-761

21. Karatza EC, Shields CL, Flanders AE, Gonzalez ME, Shields JA (2006) Pineal cyst simulating pinealoblastoma in 11 children with retinoblastoma. Arch Ophthalmol 124:595-597

22. Engel U, Gottschalk S, Niehaus L et al (2000) Cystic lesions of the pineal region-MRI and pathology. Neuroradiology 42:399_ 402

23. Golzarian J, Baleriaux D, Bank WO, Matos C, Flament-Durand J (1993) Pineal cyst: normal or pathological? Neuroradiology 35: 251-253

24. Mandera M, Marcol W, Bierzynska-Macyszyn G, Kluczewska E (2003) Pineal cysts in childhood. Childs Nerv Syst 19:750-755

25. Dunkel IJ, Jubran RF, Gururangan S et al (2010) Trilateral retinoblastoma: potentially curable with intensive chemotherapy. Pediatr Blood Cancer 54:384-387

26. de Graaf P, Goricke S, Rodjan F et al (2012) Guidelines for imaging retinoblastoma: imaging principles and MRI standardization. Pediatr Radiol 42:2-14

27. O'Brien JM (2001) Retinoblastoma: clinical presentation and the role of neuroimaging. Am J Neuroradiol 22:426-428 
28. De Ioris MA, Fidani P, Munier FL et al (2010) Successful treatment of trilateral retinoblastoma with conventional and highdose chemotherapy plus radiotherapy: a case report. J Pediatr Hematol Oncol 32:e343-e345

29. Moll AC, Imhof SM, Bouter LM et al (1996) Second primary tumors in patients with hereditary retinoblastoma: a registerbased follow-up study, 1945-1994. Int J Cancer 67:515519

30. Moll AC, Imhof SM, Schouten-van Meeteren AY, Boers M, Hofman P (2003) Chemoreduction for retinoblastoma. Arch Ophthalmol 121:1513
31. Shields CL, Meadows AT, Shields JA, Carvalho C, Smith AF (2001) Chemoreduction for retinoblastoma may prevent intracranial neuroblastic malignancy (trilateral retinoblastoma). Arch Ophthalmol 119:1269-1272

32. Turaka K, Shields CL, Meadows AT, Leahey A (2011) Second malignant neoplasms following chemoreduction with carboplatin, etoposide, and vincristine in 245 patients with intraocular retinoblastoma. Pediatr Blood Cancer 59:121-125

33. Moll AC, Imhof SM (2002) Schouten-van Meeteren AY, Boers M. Screening for pineoblastoma in patients with retinoblastoma. Arch Ophthalmol 120:1774 